\title{
Language and the Parameters of Power in Medical Discourse in Spoken Egyptian Arabic
}

\author{
Hosni M. El-dali (Corresponding author) \\ College of Humanities \& Social Sciences, United Arab Emirates \\ Email: hasan.mostafa@uaeu.ac.ae
}

Doha M. Abd El-Moety

Tanta University, Egypt

Maha A. El-Seidi

Menoufia University, Egypt

Received: $17 / 08 / 2020$

Accepted: 09/10/2020

Published: 01/11/2020

Volume: 1 Issue: 4

How to cite this paper: El-dali, H. M., El-Moety, Doha M. A., \& El-Seidi, M. A. (2020). Language and the Parameters of Power in Medical Discourse in Spoken Egyptian Arabic. Journal of Critical Studies in Language and Literature, 1(4), 28-40

DOI: https://doi.org/10.46809/jcsll.v1i4.40

Copyright (C) 2020 by author(s) and Global Talent Academy Ltd. This work is licensed under the Creative Commons Attribution International License (CC BY 4.0).

http://creativecommons.org/licenses/by/4.0/

$$
\text { (c) }(\text { i }
$$

\begin{abstract}
The present study is an investigation of the parameters of power following in medical encounters in spoken Egyptian Arabic. The analysis will focus on the aspects of discourse: speech acts especially directives such as questions, orders and commands, features related to turn taking like different types of overlap, adjacency pairs and the concept of preference, Grice's concept of implicature and the politeness theory with its strategies for Face Threatening Acts. The study aims at drawing conclusions concerning power and ways of claiming it in Egyptian Arabic medical encounters. Thus, the study differs from previous studies not only in investigating the Arabic language but also in the aspects of analysis, which has not been examined before because each of the previous studies concentrates on only one aspect of analysis.
\end{abstract}

Keywords: Medical Discourse, Power Parameters, Arab Culture vs. Western Culture

\section{Introduction}

"Language in discourse is considered "a site for and a means of the analysis of power" According to Hirsch, 1994: 12). Power is exercised when participants are unequal or when one of the participants is in a position of power. Being an institutional setting, medical encounters are said to be organized on an asymmetrical hierarchy which both the lay person and professional expertise preserve. This authority relies on expert knowledge and external social legitimation. In their interaction with patients, physicians exercise this power and even impose the discourse type upon patients: they ask questions, give commands, determine the topic, interrupt patients, and control language as a whole. Ainsworth-Vaughn (1992, 1994, and 1998) contrasts these findings emphasizing that patients are active in claiming power. These contrasting results call for more studies on the different ways participants claim power. In addition, these several studies have been 
concerned with power in English medical encounters whereas Arabic medical interactions have not received adequate attention.

In addition, no other study has focused on all these parameters of power. Previous studies have concentrated on only one or two aspects of power such as questions or topic transition (Al-Ali, 2006; Barry et al., 2006; Anderson, 1988).

\section{Statement of Problem}

Many different challenging interactions occur daily. These challenging interactions may arise due to discrepancies in expectation, perception and/or communication between the patient and medical practitioner, and could be caused by the doctor, by the patient or by both. Interactions between patients and medical practitioners can sometimes be challenging. We have all had consultations where the interaction was not optimal, either as medical practitioners or as a patient ourselves. Neither normally wishes to cause a difficult situation but common misunderstandings, by both groups, often result in such an occurrence. Communication and listening skills are essential for every consultation but in particular for situations where the interaction may become difficult. A doctor's communication and interpersonal skills encompass the ability to gather information in order to facilitate accurate diagnosis, counsel appropriately, give therapeutic instructions, and establish caring relationships with patients. These are the core clinical skills in the practice of medicine, with the ultimate goal of achieving the best outcome and patient satisfaction, which are essential for the effective delivery of health care. Basic communication skills in isolation are insufficient to create and sustain a successful therapeutic doctor-patient relationship, which consists of shared perceptions and feelings regarding the nature of the problem, goals of treatment, and psychosocial support (Boisvert \& Thiede, 2020; Bucholtz \& Hall, 2005).

The ultimate objective of any doctor-patient communication is to improve the patient's health and medical care. Studies on doctor-patient communication have demonstrated patient discontent even when many doctors considered the communication adequate or even excellent. Doctors tend to overestimate their abilities in communication. Tongue et al (2005) reported that $75 \%$ of the orthopedic surgeons surveyed believed that they communicated satisfactorily with their patients, but only $21 \%$ of the patients reported satisfactory communication with their doctors. Patient surveys have consistently shown that they want better communication with their doctors (Hall et al., 1981; Duffy et al., 2004; Fong Ha et al., 2010). Clinicians, educators, researchers, and policy advocates generally agree that a more active and autonomous role for patients in the doctor-patient relationship is necessary to address health care needs. Proponents of the patient-centered approach to health care delivery in which patients' desires and expectations are incorporated into the medical decisionmaking process so that both physicians and patients contribute to the decision-making process, suggest that eliciting and incorporating the patient perspective is associated with more favorable outcomes for patients. The evidence, however, is not conclusive. Some studies have shown that patients who are more active in the medical decision-making process report higher levels of satisfaction, adherence to treatment regimens, and medical outcomes. Other studies have failed to demonstrate a strong relationship between patient-centered care and patient outcomes. One plausible explanation for the mixed results is that the effect of the relationship between interaction style and outcomes may differ by patient characteristics (e.g., race, gender, age). Little empirical evidence exists about how patient characteristics might moderate the relationship between interaction style and outcomes. Furthermore, much of the evidence that does exist, does not examine actual doctorpatient interaction, but rather relies on preferences from vignettes and hypothetical scenarios (Peck, 2011; Bialystok, 1993; Campbell \& Roberts, 2007; Daly et al., 2004; DeFina et al., 2006).

\section{The Purpose}

The present study is an investigation of the parameters of power following in medical encounters in spoken Egyptian Arabic. The analysis will focus on the aspects of discourse: speech acts especially directives such as questions, orders and commands, features related to turn taking like different types of overlap, adjacency pairs and the concept of preference, Grice's concept of implicature and the politeness theory with its strategies for FTAs. The study aims at drawing conclusions concerning power and ways of claiming it in Egyptian Arabic medical encounters. Thus, the study differs from previous studies not only in investigating the Arabic language but also in the aspects of analysis which has not been examined before because each of the previous studies concentrates one aspect of analysis. Further, the results of the analysis will be compared to those of western culture to see whether they are similar or different concerning power in medical discourse.

\section{Methodology}

The database consists of 143 minutes of audio-recorded medical encounters between Egyptian physicians and patients in both private and public practice settings. It includes 28 encounters: 14 in public clinics and 14 in private practice settings. Most of the encounters were initial visits. Only five encounters were repeat visits, which took place in private practice settings. The data were collected over a period of two years. Encounters in public clinics were audio taped in two public hospitals. Prior to the taping, a brief description of the purpose of the study was given to the physicians. The description states that the study is about doctor-patient interaction. Nothing was said about power or different ways of claiming it.

4.1. Data Collection Procedure 
The data have been collected in two different ways. First, in public clinics, the researcher attended the encounters that were audio-taped. After each encounter physicians tended to explain the case in detail deliver the diagnosis and even restate the details of treatment to the researcher. Second, in private practice settings the physicians themselves were asked to audio tape the encounters. The data were then written in its colloquial Egyptian form. Each encounter has been given a number. Further, details of information about physicians and patients were noted. Then, the data were phonetically transcribed with the following kinds of information available in the transcript file: (1) time and place of the original recording, (2) identification of the participants, (3) words as spoken, (4) sounds as uttered, (5) spaces silences, (6) overlapped speech, and (7) rising intonation.

\subsection{Participants}

The medical doctors participate in this study by accepting to have their encounters with patients recorded five in public clinics and five in private practice settings. Of the ten physicians participating in the study, there were nine males and only one female. The ages vary between late twenties to early forties. They belong to the following specialties: pediatrics, nephrology, dermatology and internal medicine. Patients in the study can be divided into three groups according to age: the group of young children and babies, middle-aged patients, and patients aged over sixty. In the first group the interaction was between the physician and one or both of the parents. Concerning the socio-economic status of patients, two different categories have been observed. The categories correspond to the division of encounters into public and private. Category one is for patients in public clinics, who belong to the working class. They are either uneducated or with very limited education. Category two includes patients in private practice settings to the middle class. Although most of them are educated, some are uneducated.

\subsection{The Framework of Analysis}

The study falls within the theoretical framework of oral discourse analysis. It attempts to discover power relations between participants through analyzing their organizational strategies. Participants are seen as constructing unique speech activities which they choose according to the context. In this regard, the study belongs to the domain of qualitative research with its emphasis on the relationship between choice and context. Qualitative research uses naturalistic data which are familiar to participants to reveal the way talk is organized into appropriate sequences. Yet, some aspects of the qualitative research are not included in this study. First, the study does not depend on either participant observation or "participant's views". Second, it handles many encounters rather than focusing on only one or few encounters. Finally, it will depend on definitions and counting. Hence, the study also belongs to the area of quantitative research. In other words, the study depends on a synthesis of both quantitative and qualitative approaches (Hart, 2020 \& Have, 1999).

The way the medical encounter is structured is of central importance for the investigation of the parameters of power. Thus, the selection of actions and their verbal shapes; turn-taking systematics, including overlap and interruptions; sequence organization, different types of politeness and deviations from the co-operative principle with its maxims will be analyzed using the tools of spoken discourse analysis. These are selected because they represent some of the ways of claiming power in medical encounters. Other aspects of analysis such as turn construction unit are out of the scope of the present study since most of the encounters include only two participants. In such case, next speaker's selection is always obvious.

4.4. Stages of Analysis

\subsubsection{Transcribing the Data}

Transcription is a distinctive stage in the process of data analysis. It is a selective process that reflects theoretical goals and definitions. Yet, it cannot capture all the possible features of talk. Kendon (1982: 478) observes that "it is a mistake to think that there can be truly neutral transcription system, which if only we had it, we could then use to produce transcriptions suitable for any kind of investigation ...Transcriptions thus embody hypotheses. Thus, the transcription conventions used will focus on features related to both turn- taking and speech delivery. The conventions used are a synthesis of those used by Ezzat (1972) and Hafez (1988). Identification of the participants is indicated by letters such as Dr. and P. for doctor and patient respectively.

\subsubsection{Testing the Data}

After the process of transcription, the data have been tested for possible criteria of analysis. Thus, some encounters in which the medical phases are incomplete and those in which conversational features cannot be observed are excluded. For the analysis of speech acts, both linguistic and discourse criteria were examined. When there are redundant defining features, the following order of priority is credited: syntax, phonology, then discourse.

\subsubsection{Classification}

Speech acts and conversational features will be classified. That is speech acts are classified into directives which are further sub-classified into questions, orders/commands and requests. Questions themselves are classified according to linguistic and contextual criteria. For example, there will be seeking information questions, yes/no questions, choice questions, and question tags. Likewise, overlap will be classified into transitional overlap, interruption, and Backchannels. Politeness strategies will also be classified into four categories: bald-on-record, positive politeness, negative politeness, and off record. Each category will then be analyzed into utterances such as (include both speaker and hearer in the activity, give deference, and be vague). 


\subsubsection{The Analysis of the Data (Procedure and Rationale)}

The analysis of the data will proceed as follows: First, the parameters of power in the interactants' linguistic behaviour outlined in the previous sections will be defined. Second, they will be classified into (sub)-categories. The relative frequency for each (sub)-category will be measured. This will be followed by an attempt to interpret the results in terms of context. Finally, there will be a comparison between the results in public and private practice settings to draw conclusions about power and ways of claiming it in Egyptian Arabic medical discourse.

\section{Review of Literature}

\subsection{Previous Research on Doctor-Patient Interaction}

The structure of talk in doctor-patient interaction reflects speakers' orientation to its institutional nature and context. Through the use of technical jargon or vocabularies, speakers indicate their institutional identity. Also, their lexical choice is said to be context sensitive. For example, Sacks (1992) observes that members of institutional organizations refer to themselves as 'we' rather than 'I' to indicate that they are speaking as representatives or on behalf of an organization. This leads to analyses focusing on the use of 'we' and 'I' by doctors. Related to lexical choice is the use of temporal references which Schegloff (1972) discusses. He refers to the different use of terms related to temporal references in ordinary conversations and institutional context (Yazdannik \& Mohammadi, 2017). Structural organization does also include turn design, sequence organization, and cautiousness. Analyses of turn design show that it consists of two distinct phenomena: a) the selection of an action to be accomplished in the turn; and b) the selection of the verbal shape. As for sequence organization, it refers to the sequential nature of the interaction which draws-upon-basic conversational phenomenon Silverman (1987) illustrates how "institutional" properties of talk are identified through ordinary conversational phenomena by providing an extract from an investigation of a cleft- palate clinic in which the doctor's attempt to determine if the patient wants to undergo further surgery arises misunderstanding, an overlap/ interruption, and a topic change. In addition to these features of institutional interactions which are evident in doctor- patient talk, there is power asymmetry which both physicians and laypersons are aware of the following section will illustrate this power asymmetry (Peck, 2011; Hardavella et al., 2017; El-dali, 2019a,b; 2012, 2011).

5.2. Asymmetry in Doctor-Patient Talk

Parsons (1951) observes that there is a "communication gap" between doctors and patients. This gap arises from the professional competent help patients need. For him, patients are neither qualified to do what is needed nor able to judge what needs to be done. So, he draws the attention towards the asymmetrical relationship between doctors and patients in medical consultations. This asymmetry has been observed in the phases of medical consultations and in the way diagnosis has been delivered and received. Byrne and Long (1976) divide medical consultations into the following phases in which physicians practice their power and influence over patients: (1) relating to the patient, (2) discovering the reason for attendance, (3) conducting a verbal or physical examination or both, (4) consideration of the patient's condition (diagenesis), (5) detailing treatment of further investigation and (6) terminating. They observe that phase (4) of the consultation in which the diagnosis or medical assessment is presented is limited and sometimes it does not exist at all and this is related to the asymmetries of the relationship. The asymmetries related to delivering and receiving diagnosis, on the other hand, have been studied by Heath (1992). She observes that diagnosis, varying from a single word or phrase to a detailed description of the condition, is designed by doctors in two distinct ways: a) as a factual monolithic assertion; or b) as a 'question'. The patient's response, then, in each way is different. However, patients do not always remain silent. They may produce a response in the form of a downward-intoned er or yeh which shows that the patient acknowledges the diagnosis, passes the floor back to the doctor, and provides him with an opportunity to develop the interaction as he likes patients also in representing and displaying the seriousness of their symptoms, encourage doctors to reconsider their opinions. Patients are not always passive. Asymmetry is also evident in "the discourse type" which doctors are said to impose upon patients. It includes questions, orders, commands, interruptions, and topic initiation and/shifts. Interest in questions is drawn from the conclusion that 'medical encounters' are an "interview genre" in which one asks questions, and the other passively answers. In addition, Dillon (1990) observes that questions are a principal device, which doctors use in communicating with patients. Roter (1977) also states that patients are passive and powerless because they rarely ask questions. Thus questioning has crucial functions in medical encounters to the extent that its use is an indicator of claiming power and control over the discourse. Questions constitute a powerful discourse move for the following reasons. First, a question nominates the next speaker. Second, it sets the topic of the response. Third, it indicates that the floor will be returned back to the questioner. Finally, it elicits information which empowers its possessor (Fong Ha et al., 2010; Hall et al., 1981; Duffy et al., 2004; Givon, 2005; Gotti \& Salager-Meyer, 2008).

\section{Analysis and Discussion}

This section provides an analysis of the database and the discussion of the results. The analysis will focus on two main aspects of Egyptian Arabic medical encounters: the characteristics and the structural organization. Then, it will provide a discussion of the results, compare them with previous studies and draw conclusions about ways of claiming power in both public and private practice settings in Egyptian Arabic medical discourse. 


\subsection{Characteristics}

The encounters have certain specific phases which physicians always seem to preserve. These phases are generally comparable to those listed by Byrne and Long (1976) in their study of doctors' verbal behaviour. According to Byrne and Long, medical consultations contain six distinct phases: phase I, relating to the patient; phase II, discovering the reason for attendance; phase III, conducting a verbal or physical examination or both; phase IV, diagnosis; phase V, detailing treatment or further investigation; and phase VI, terminating. The present study demonstrates differences in both the number and type of phases according to whether the interaction takes place in a private or public practice setting. In private practice settings, with the exception of repeat visits, the encounters have the same six phases with only one difference: phase I is related to the doctor rather than to the patient, i.e., with the exception of the adjacency pair greeting/greeting which is initiated by the patient, physicians seem always to initiate the verbal interaction. In phase I, the pediatrician initiates the verbal interaction and determines the topic Phase II contains sequences of adjacency pairs questions/answers in which the pediatrician inquires about the reason for attendance. In phase III, he conducts a verbal examination followed by a physical one. Then in phase IV, he delivers the diagnosis followed by the details of treatment in phase V. Finally, phase VI terminates the encounter. In public practice settings, the analysis has shown different results regarding these phases. First, phase I, which is related to the doctor, in private practice settings is either missing or contains a single utterance by the physician inquiring about the reason for the attendance. Second, Phase IV in which the diagnosis is provided is always missing. Physicians tend to move from phase III of conducting the examination to phase V of detailing treatment without referring to diagnosis. Third, phase VI of terminating is expressed non-verbally, i.e., both physicians and patients take phase $\mathrm{V}$ of detailing treatment as a termination for the encounter. Consequently, patients leave as soon as the physician details treatment (Hammudin, 2012; Harris, 2003; Haworth, 2006).

The medical consultation in public clinics has the following phases: phase II. Discovering the reason for attendance, phase III. Conducting a verbal and/or physical examination; and phase V. detailing treatment. Phase II is expressed nonverbally when the mother shows the baby's body to the physician. Then phase III starts in which the physician conducts his examination. This is followed by phase $\mathrm{V}$ of detailing treatment. Then the mother takes the end of this phase as a termination for the consultation and leaves. In this regard, it appears that there is power asymmetry in the relationship between physicians and patients in Egyptian Arabic medical encounters. It arises mainly from the help patients need and the specialized and technical knowledge physicians have. Being ignorant of both the nature and the treatment of their diseases, patients are less powerful than physicians who determine the nature of the patient's condition and its appropriate management. Such type of power is gained through what West and Zimmerman (1985) call situated identities. Physicians acquire power through the medical institutions which they represent. Asymmetrical relationship is manifested in the phases of medical encounters and their structural organization. Concerning the phases of medical encounters in private practice settings, phase one reveals doctors' dominance and control over the verbal interaction. This control over phase one contrasts with Byrne and Long's (1976) finding that phase one is related to the patient. In the present data, physicians imitate the encounters with patients and determine the topic. In this extract, the physician initiates the verbal interaction with the mother of the patient. Then, he shifts the topic and moves to phase two in which he asks about the reason for attendance. Another difference between these results and those of the previous studies is found in phase IV. Byrne and Long observe that phase $\mathrm{IV}$, in which the diagnosis is provided, is either limited or completely absent. By contrast, phase IV is present in all the encounters of private practice settings in the form of a detailed description of the condition. Even in repeat visits where diagnosis is already known, physicians tend to provide a consideration of the condition in relation to initial visits. In this extract, the physician provides a consideration of the patient's condition in relation to the initial visit and also refers to the prescribed treatment. The way diagnosis is received is also different from previous studies. In the present data, patients respond to the diagnosis with an agreement, a disagreement, or a question. This contrasts with the findings of Heath (1992) that patients respond to the diagnosis by either remaining silent or by producing a downward intoned 'er' or 'yeh'.

In some cases, the patients respond to the physician's consideration of her condition with a disagreement. In other cases, patients respond to diagnosis with a question. Thus, both the delivering and receiving of diagnosis in private practice settings is different from the findings of Heath (1992). In terms of power, patients are not passive and physicians' control and influence over medical consultations is not static. There is a power sharing between physicians and patients, i.e. physicians control the verbal interaction and determine the topic in phase I, yet, in phase IV, they provide patients with the diagnosis and patients themselves do not remain silent. Rather, they produce different types of response. In public practice settings, on the other hand, the results are different. Phase I is either missing or contains a single utterance by the physician that inquires about the reason for attendance. This contrasts with the finding of Byrne and Long that phase I is relating to the patient. Phase IV in which the diagnosis is provided is also missing. Physicians move from phase III of conducting verbal and/or physical examination to phase V of detailing treatment. Also, phase VI is either missing or expressed non-verbally. Both physicians and patients take phase $\mathrm{V}$ in which treatment is given as the termination for the encounter. This is due to the asymmetrical relationship between physicians and patients. In addition to situated and/or institutional power, physicians in public practice settings have master identities: power gained through social class. Yet, this power is also dynamic as demonstrated in the doctors' performance in private practice settings. This is demonstrated by the way patients ask about the diagnosis ignored by physicians. Thus, patients are not passive. They claim power in the phases of medical consultations. Even when physicians design turns in a way as to ignore the delivering of the diagnosis, patients ask about this diagnosis rather than remaining silent (Evans, 2018; Heydon, 2005). 


\subsection{The Structural Organization}

The analysis of the data focuses on turn-design, sequence organization, turn-taking organization, lexical choice, and other parameters of power including the co-operative principle and the politeness theory. The following sections will illustrate these points in detail.

\subsubsection{Turn-design}

The design of turns in these encounters reflects physicians' and patients' orientation to context. There are three different types of speech acts in these encounters: representatives including statements, expressives such as greetings, and directives like questions, commands, and requests. Yet, the most commonly used type was the class of directive speech acts. The following sub-section handles the three types of directive speech acts.

\subsubsection{Questions}

The questions are identified according to syntactic and/or phonological form. Both physicians and patients asked questions. Of the 362 questions identified in the data, 149 questions, were asked by patients and 213 were asked by physicians. Moreover, the results vary as to whether the encounters belong to private or public practice settings. In public practice settings, physicians' questions are almost twice as many as those of the patients: there were 109 questions asked by physicians versus 58 questions asked by patients. In private practice settings, on the other hand, physicians' questions are only slightly more frequent than those of patients: patients asked 91 questions of 195 questions identified in the data and physicians asked 104 questions. The questions include the following types: information-seeking questions, yes/no questions, choice questions, and tag questions according to the intonation and the context in which they occur and according to the sentence structure. Thus, patients are not passive. They claim power in the phases of medical consultations. Even when physicians design turns in a way as to ignore the delivering of the diagnosis, patients ask about this diagnosis rather than remaining silent. Thus, patients asked a high percentage of questions which is considered a means for claiming power. Questions are indicators of power: they nominate the next speaker, determine both the topic and type of response, entail that the floor will be back to the questioner, and aim to elicit information which empowers its possessor. As pointed out above, physicians' questions were more frequent than patients'. Yet, in private practice settings physicians' questions are slightly. more frequent than those of patients while in public clinics they are almost twice as many as those of the patients. This high frequency of the questions patients asked especially in private practice settings contrasts with the findings of Roter (1977), and Frankel (1990). The results, on the other hand are similar to those of Ainsworth-Vaughn (1994, 1998). In terms of power, patients are not passive: they claim power by asking questions. Yet, the results indicate that the type and context of physicians' questions are different from those of patients. Physicians' questions are intended to acquire information from the patient about his/her disease and its symptom. Such information is essential before the diagnosis and the detailing of treatment. So, physicians' questions come in the first three phases of the encounter: relating to the doctor, discovering the reason for attendance and conducting the verbal and/or physical examination. By contrast, patients' questions are intended to obtain information about the diagnosis, types of treatment, its duration, the possibility of recovering and whether there is a need for further investigations or repeat visits or not. This leads to questions directed by patients in phase IV diagnosis, phase $\mathrm{V}$ detailing treatment and phase VI of terminating.

In this context, questions can be analyzed in two different ways as an aspect of sequence organization, and/or as an aspect of professional dominance. First, the encounter can be viewed as a request from the patient for the physician's assistance, professional diagnosis and treatment which in turn requires additional information for the physician. This information is acquired through a series of insertion sequences, namely, questions/answers between the two parts of the pair. Second, as illustrated in the present study, questions are analyzed as an aspect of professional dominance. The results reveal two important factors: first, patients claim power by asking questions, and second, Egyptian Arabic medical encounters do not belong entirely to the interview genre in which one participant asks and the other passively answers. Rather, they are examples of what Schegloff (1987) calls talk-in-interaction (Holmes, 2005).

\subsubsection{Commands}

There are 144 commands in these encounters: 72 in public clinics and 72 in private practice settings. The commands were all given by physicians to patients in two main phases: phase III of conducting the examination and phase $\mathrm{V}$ of detailing treatment. They are expressed either in the form of a direct imperative or in the form of a statement. The following examples illustrate these various forms for commands. Orders exert power and control over other conversational participants. They are also intrinsically face-threatening acts because they contradict the face wants of the addressee by putting pressure on him/her to do them. Physicians' commands were given in various forms: a statement or a direct imperative. They are in conformity with Grice's maxims. They are expressed in the most direct clear and unambiguous way. They conform to the maxims, which are the guidelines for achieving maximally efficient communication. There are various reasons for the use of the bald-onrecord strategy: cases of great urgency or seriousness, cases of power superiority, cases in which the doing of the FTA is in the interest of the addressee, and rituals for beginning and terminating encounters such as greetings and farewells. In the present data the commands are given in phases III and V. That is, in the phase of examination and in the phase of detailing treatment. In these two phases, maximum efficiency is very important. Hence, physicians choose the bald-on-record utterances: the clear and direct way for achieving maximum efficiency. Further, the FTA itself (the command) is in the interest of the patient: it either helps in the physical examination or clarifies the details of treatment. In this regard, the commands are not intended to reveal physicians' superiority over patients. The commands are restricted to phase III and V. 
In addition, physicians resort to strategies of politeness- negative, positive, and off record to give attention to patients face (Kamp \& Partee, 2004; Jiang, 2006).

6.2.1.3. Requests

There is only a few number of requests in these encounters. They were all directed by patients to physicians. There are two requests in public clines and three in private practice settings. Generally, requests were accompanied by negative politeness features such as hedges and give deference. Of the hedges found in these encounters are "bass" meaning "but", "Tabb" meaning "OK", and "mi/ mumkin" meaning "isn't it possible". As for the use of give deference strategy in requests, there were two common utterances: "haDritik" meaning "your honour" and "ya duktuur" meaning "doctor". In the following example, the mother does not only preface her request with the hedge 'bass', 'but', but also includes ' 'haDritik', "your honour".

\subsection{Sequence Organization}

These encounters are sequentially organized as each utterance is produced in a certain specific place. It is related to the preceding one and at the same time it creates a context for its own next utterance. Adjacency pairs, preference system, and topic change provide major instruments for this analysis. The following section will discuss each one in detail.

6.3.1. Adjacency Pairs and Preference System

There are two different types of adjacency pairs in these encounters: greeting/greeting and question/answer. The first pair part was commonly used in the opening of encounters in private practice settings. By contrast, the second kind of adjacency pair was commonly used in both private and public practice settings due to the nature of the interaction. This simple form for the question/answer pair is an indication for the preference system, i.e. questions are followed by answers rather than by not answering. Yet there are cases in which this simple form is not present. Questions are sometimes followed by a pause which leads the questioner to repeat his/her question until an answer is obtained. In other cases, the physician's question is responded to with another question rather than with an answer. In this encounter, the physician's question in 1 is responded to with another question in 3 by the patient. In 4 the physician responds to the patient's question with an answer which was followed by an answer for the physician's first question. This is a case in which there is an adjacency pair within another: /question (question/answer) answer. Thus, the question/answer pair is the most frequently used one. This is due to the nature of the interaction. i.e. institutional interaction. Yet, the shape of the encounters is always negotiated by physicians and patients rather than being pre-allocated. This is illustrated by the different shapes of the adjacency pair question/answer. Also, the way this pair is designed is $\mathrm{m}$ indication of the inferential property of sequences (McKellin e al., 2007; Mooney et al., 2011).

Physicians design their first parts in particular ways in order to get certain social actions done and patients also, in return, can design their second parts as preferred or dispreferred responses. Instead, she combined the two alternatives: it appears and vanishes and at the same time there remains traces. This indicates the conversational nature of these encounters. Furthermore, patients' design of their second parts as preferred and dispreferred responses and their design of questions are illustrations of the power they have. They are not constrained to respond in a certain specific way as in court cases discussed by Levinson (1992). They are free to design their utterances as questions and to get answers from physicians and they are free to design their responses in different forms, i.e. preferred, dispreferred, pause, or another question (Simpson et al., 2018). 6.3.2. Topic Change

There are two means for changing topic in these encounters: smooth and sudden. Physicians resort to smooth transition in the phases of the encounter. They move from one phase to another smoothly. The physician considers the patient's answer for his question as the end for phase III of conducting the examination. So, he moves to the following phase in which he details treatment. Sudden topic change, on the other hand is carried out by patients in the form of questions. Physicians respond to these sudden topic change questions with answers. Yet, sometimes physicians challenge topic change and keep the on-going topic.

\subsection{Turn Taking Organization}

In addition to these features of the sequence organization of the encounters, the analysis focuses on organization features such as overlap, interruption and backchannels. Transitional overlap refers to the misjudgment overlap by current non speaker who starts his/her turn of possible transition relevance place while the current speaker continues. Interruptions, on the other hand, are cases in which current non-speaker claims the right to a turn before the completion of current speaker's turn. As for backchannels, they are feedback vocalizations produced by current non-speaker during a current speaker's on going utterance but without claiming the speaking turn. Though physicians and patients observed the rules for smooth transition between turns, occurrences of more than one speaker at a time were common. The following section is designed to shed light on these features.

\subsubsection{Transitional Overlap}

There were 17 cases of overlap at possible transition relevance places. There were 10 occurrences of transitional overlap in private practice settings and 7 cases in public clinics. Contrary to expectations, doctors do more overlapping in the private settings than in the public ones. There were 7 cases of transitional overlap carried out by physicians in private practice settings opposed to 4 cases by physicians in public practice settings. Thus, transitional overlap occurs in both private and public practice settings. Regardless of the asymmetrical relationship, current non speaker's turn taking is hierarchically prior to continuation by current speaker. In one encounter, the mother of the baby overlaps with the female physician before the completion of her turn. This overlap is resolved by the physician yielding the floor to the mother to answer a question that 
has not been completed. In the following example, by contrast, the physician overlaps with the mother of the baby. This occurs when the physician starts a turn about a consideration of the condition before the mother's completion of her turn. The overlap is resolved by the mother yielding the floor to the physician who starts a new turn and changes the topic.

Thus, turn-taking priority by current non-speaker may be due to the type of the utterance itself rather than to the social distance between participants. That is, it may be related to the discourse identity. Current non-speakers start their turns with directives such as questions and orders, parts of adjacency pairs which are preferred such as answers to questions, clarifications and/or a consideration of the condition. In this sense, transitional overlap displays negotiation, interest and understanding rather than social distance. This is similar to Tannen's (1987, p.77) finding that transitional overlap reveals "solidarity, enthusiasm and interest in other's talk".

\subsubsection{Interruptions}

Cases in which one of the participants claims the right to a turn before the completion of another's were also common in these encounters. Of the 67 Interruptions that occurred in these encounters, physicians were interrupted 33 times by patients and patients were interrupted 44 times. Moreover, physicians in private practice settings interrupted patients more than they do in public clinics. Therefore, when current non-speaker starts his turn at a point, which is not a transition relevance place (TRP) the result, is a competitive act called interruption. One of the participants in his /her attempt to dominate and control the conversation considers an interruption. As such, it is a violation of a current speaker's right to complete a turn or even to reach at a possible TRP. In dealing with interruption, either current speaker may yield the floor accepting non-speaker's interruption to resolve the resulting overlap or he may use negative sanctions such as complaints. In the present data, both types of response occur. In the following example, the physician claims the right to a turn by starting before the mother of an eighteen-month-old baby completes her rum or even arrives at a possible transition relevance place (PTRP). Yet, the mother in order to resolve the resulting overlap, yields the floor and stops prematurely, thus effecting a break. However, participants in medical consultations do not always respond by yielding the floor. Interruption is negatively sanctioned by the physician who has been interrupted by the mother of the patient more than once in the encounter. Interruptions are marked by certain strategies for taking the speaking turn without waiting for the transition relevance place TRP. S/he may preface the turn with an attention-getter like 'bass' (but) "Tab" (so) or "yacnii" (thus),. The following example illustrates this use of attention-getter by interrupter. The patient prefaces her turn with the attention-getter 'bass' (but) to claim the speaking turn.

Although interruption is an attempt by one of the participants to dominate and control conversations, the present data show that both physicians and patients interrupt one another. Interruptions occur for various reasons. First, physicians interrupt patients to ask questions or give commands in conducting the examination. They interrupt patients to get certain specific information needed before the diagnosis. For the physician, what the mother is saying is not as important as the question about the pimples' appearance. Consequently, the physician interrupts the mother before she completes her turn and the mother yields the floor and responds in the following turn with an answer to the question. The other case in which physicians may interrupt patients are related to giving commands. Second, physicians interrupt patients to clarify their utterances. Third, patients interrupt physicians to ask questions in the phase of detailing the treatment. Fourth, patients interrupt physicians to say something, which they believe to be important. The patient interrupts the physician whose question indicates that there is either an infection or a hereditary disease. Therefore, the patient interrupts the physician to reveal important information, which, he believes, may affect the physician's diagnosis. Finally, patients interrupt physicians to express an agreement or a contradiction to what the physician says.

In terms of power, interruption in medical encounters is not just an attempt to dominate and control. It has other functions to be fulfilled by physicians and patients. However, the different types of response to interruption indicates power asymmetry: only physicians have the power to respond to an interruption with negative sanctions. Patients, on the other hand can respond to interruptions only by yielding the floor. This is due to situated and institutional identities, which physicians possess.

\subsubsection{Backchannels}

The encounters were also characterized by the frequent use of backchannels. Of the 106 backchannels found in the encounters, there were 40 backchannels produced by physicians and 66 produced by patients. Yet, physicians' production of backchannels in private practice settings was more frequent than its counterpart in public clinics. In the present data, backchannels consist of brief utterances in the form of non-verbal vocalizations such as "hah" "hmm" and "? mm" "um" one or two word utterances like "Tayyib" - OK, "?aywa"-"yes" and "maafii"- "No" or a repetition of all or part of the previous turn by the current non-speaker. In the following example, the physician responds to the patient's utterances by producing backchannels to indicate attentive hearership. Backchannel vocalizations serve to display continuing interest and co-operation in topic development. They indicate that the listener, who is doing support work, is carefully attending to the stream of talk. In the present data, backchannels were common. Yet patients' backchannels were more frequent than those of physicians. They were used to fulfill a variety of functions. Physicians and patients produce backchannels to confirm the continued attention and hearership. Physicians can also use backchannels to show sympathy with patient's statements. Patients, on the other hand, produce backchannels to acknowledge understanding of the physician's speech. Thus, most of the patients, backchannels were produced in the phases of diagnosis and detailing treatment.

The interpretation of such violations for the turn taking is based on Sacks et al. (1987) assumption that the turn-taking system is an economy in which the distribution of turns is like a commodity. In this sense, differences between physicians 
and patients in turn distribution can be considered a matter of advantage. Furthermore, cases of more than one speaker at a time are considered violations that should be justified. In this regard, turn taking violations can be justified as follows. Transitional overlap indicates the negotiate nature of the medical consultations. Physicians and patients negotiate rights to turn-taking through misjudgment overlap and the fact that this overlap is soon resolved indicates their orientation to the "one speaker at a time" strategy. Interruptions, by contrast, reveal a competitive behaviour on the part of the interrupter. When used frequently, they assert the speaker's authority and lack of care for the interrupters face. In the present data, however, interruptions were not frequently used. Further, both physicians and patients used them to achieve certain functions. Similarly, back channels were produced by participants to achieve a variety of functions. They are co-operative overlaps that indicate non-speaker's continued attentions, understanding, agreement and interest. These three types of overlap can be ordered according to their frequency of occurrence as follows: backchannel vocalizations, transitional overlap and interruptions. In terms of power, medical consultations are characterized by co-operation and positive reinforcement for continued talk from both physicians and patients. There is no absolutely powerful or powerless participants. Rather both participants are active hearers that pay considerable attention to one another. Yet there is some sort of power asymmetry, which characterizes these encounters. It is due to this power asymmetry that responses to interruptions vary (Van Dijk, 2006, 2008a, b; Wang, 2006).

\subsection{Lexical Choice}

Lexical choice focuses on items that reflect participants' orientation to the institutional nature of the encounters. It includes the use of technical jargon and professional cautiousness. The following section discusses each one in detail.

6.5.1. The Use of Technical Jargon

The analysis of the data shows contrasting results between public and private practice settings. In public clinics, physicians tend to avoid the use of technical terms. In private practice settings, by contrast, physicians tend to use technical jargon. There were 31 cases of the use of technical terms by physicians. Moreover, the encounters include lots of utterances in which physicians discuss these terms with patients to get them to understand their conditions.

6.5.2. Professional cautiousness

The encounters include 20 utterances that were designed in a way to maintain cautiousness. Physicians reflect their orientation to their institutional tasks when they resort to using general statements and indirect speech acts. First, physician begins his turn with the question who tells you so? Which conveys the possibility that there may be another person who is responsible for such a fault rather than asserting that it is the mother's fault? Second, he asks two rhetorical questions to let the mother infer that it is only the physician who has the right to prescribe medicine. Finally, he states the danger of injecting the child.

The analysis of lexical choice reflects the dynamic nature of the power asymmetry between physicians and patients. In public clinics, physicians avoid the use of technical vocabulary terms though they exercise two different types of power over patients, i.e., institutional identity and master identity. Therefore, the avoidance of technical vocabulary jargon may be a means of decreasing the social distance between physicians and patients. Furthermore, it may also be indicated to encourage patients' participation in the verbal interaction. By contrast, physicians in private practice settings tend to use technical vocabulary items. Yet, they are not intended to show power superiority over patients. Rather, physicians provide patients with necessary explanations for these terms. As such, the social distance between participants does not remain static. It is increased and decreased during the encounters and physicians do not always aim to indicate and practice power superiority over patients. By contrast, they provide patients with opportunities to power claiming (Widdowson, 2004; Wilce, 2009).

\subsection{The Co-Operative Principle}

The 144 commands given by physicians in phase III of conducting the examination and in phase V of detailing the treatment are in conformity with Grice's maxims. They are given in the clearest and most direct way. Physicians resort to bald-on-record strategy and design their commands as imperatives or statements. In the following encounter, the physician designs his command as a statement that conforms to Grice's maxims of Quantity, Quality, Relation, and Manner. In addition to these commands, the encounters include other utterances in which physicians flout Grice's maxims by inviting implicature. In the following example, the physician responds to the mother's question by violating the maxim of manner and thus being less informative than is required. Yet, the physician intends this flout of maxim to avoid saying that the child has scabies. Thus, there is an observation for the co-operative principle and its maxims. This is due to the nature of the interaction in these encounters in which achieving maximally efficient communication is the most important aim. Thus, physicians and patients produce utterances that are clear, direct and unambiguous. They conform to the maxims of Quantity, Quality, Relation and Manner. However, there are instances in which physicians flout these maxims and invite conversational implicature to avoid responsibility for doing an FTA. This indicates two important observations: First, the encounters have the purposeful and co-operative nature of conversations. Second, they refer to the importance of context in interpretation and the observation for face consideration.

\subsection{The Politeness Theory}

Although the achievement of efficient communication is the most important aim in these encounters, cases in which participants give attention to each other's face were common. These cases of face considerations came in the form of positive politeness, negative politeness and in the use of the off-record strategy. There were 131 utterances in the form of positive politeness: physicians in private practice settings gave 93 utterances and 38 in public clinics. They were expressed 
linguistically. In addition to positive politeness, the encounters include instances in which participants aim at minimizing the particular imposition that the FTA unavoidably effects. This is done with negative politeness. In private practice settings, there were 38 utterances of negative politeness while in public clinics there were 20 such utterances. That is, cases of negative politeness are more frequent in the private settings than in the public ones. Furthermore, patients' use of this strategy is more common than physicians, use of it. Out of the 58 utterances identified, there were 45 utterances produced by patients and only 13 utterances by physicians. Negative politeness is implemented by the following strategies: (1) Stating FTA as a general rule - In this strategy, physicians displace patients and state the FTA as a rule in order not to blame them directly for doing something wrong. Thus, in the previous example, the physician avoids saying something like "what you have done is wrong and it may affect your child's health badly". This utterance came in response to the mother's indication that she gave her child "novalgin". (2) Minimize the imposition; (3) Give deference - Both physicians and patientsuse this strategy. Yet, patients' use of it is found to be more common than that of physicians. (4) A hedge: a particle, a word, or a phrase that modifies the degree of membership of a predicate or noun phrase in a set; (5) Apologize - When patients do an act, which they believe to be an FTA, they tend to apologize as the following example indicates. The patient raises his foot in front of the physician to let him see how it is injured in the physical examination phase. Yet, the patient accompanies this act with an apology. (6). Impersonalize speaker and hearer - Physicians resort to this strategy to minimize the imposition that the FTA affects. In the following encounter, the physician avoids the use of 'I' and 'we' to encourage the patient to respond freely.

In addition to positive and negative and negative politeness, physicians use off-record strategy and invite conversational implicature through violating Gricean Maxims of efficient communication. Yet, off-record utterances were not common in the encounters. There were only 6 utterances in which physicians flout Grice's maxims. They were used to help them do an FTA without having the responsibility for doing it. In the present data, off-record strategy is linguistically realized as follows: be vague, give hint; and use rhetorical questions. (1) Be vague: violate the Manner Maxim- By violating the manner maxim, the physician indicates the serious condition of the patient under examination. Furthermore, this utterance has been provided as a preliminary to the diagnosis and it may also indicate the parents' responsibility for such a bad condition. (2). Give hints: violate the relevance maxim - The physician may give hints about the serious and bad condition of a patient by violating the Relevance maxim. (3). Use rhetorical questions: Violate the quality maxim - The physician uses rhetorical questions and violates the Quality maxim to indicate that it is only the physician who has the right to prescribe medicine and to criticize the patient's behaviour in taking the medicine irregularly.

Generally, politeness strategies were more commonly used in private practice settings than in public clinics. This is an indication of the differences in power relations between participants in the two settings. In public clinics, physicians exercise more power over patients. Consequently, they pay little attention to patients' face while patients' utterance, show great considerations to physicians' face. By contrast, in private practice settings, physicians show a considerable attention to patients' face. Yet, the social distance between physicians and patients is a dynamic one. It is negotiated with positive politeness and negative politeness, which work as a social "accelerator" and social "brake", (Brown and Levinson 1978) for increasing and decreasing social distance in medical consultations. The use of the negative politeness strategy "give Deference", for example, increases the social distance whereas the use of the positive politeness strategy "presuppose/raise/assert common ground" decreases it. Thus, positive and negative politeness strategies provide physicians and patients with a means through which they can keep and assert the dynamic nature of their relationship.

\section{Conclusion}

The study is about language and power in Egyptian Arabic doctor-patient interaction. In the present study patients are neither passive nor powerless. In these encounters, there is power asymmetry between physicians and patients. It arises from the status and role that physicians occupy. It is an institutional and legitimated power. This power is reflected in the discourse, especially in the phases, which physicians seem to preserve. Yet, the results vary according to whether the encounter is in a private or public practice setting. This is because physicians in public practice settings exercise a different type of power in addition to institutional power. It is the power gained through social class.

In private practice settings, physicians' power is manifested in phase $I$ in which they initiate the verbal interaction and choose the topic. Yet, this control is negotiated and physicians' power is not static. Physicians are not constantly the powerful participants nor are the patients constantly the powerless ones. In phase IV, physicians provide patients with the diagnosis, which empowers patients, and patients themselves respond to this diagnosis with a question, an agreement or a disagreement. Likewise, in public practice settings, there is a share of power though in different phases. Physicians' power in these encounters is higher and the distance between physicians and patients is larger. This results in the short duration of encounters and consequently the absence of certain phases. Phase I is either absent, expressed non- verbally or includes just one utterance by the physician about the reason for attendance. Similarly, phase IV in which the diagnosis is provided and phase VI of terminating are missing. The absence of these phases, especially the provision of diagnostic information in the consultation, is related to the asymmetries of the relationship and the maintenance of medical authority. Yet, this maintenance is not absolute: patients ask about the diagnosis.

Power is also negotiated through the structural organization of medical consultations. Of the total number of questions identified in these encounters, $40.8 \%$ were asked by patients. In private practice settings, patients asked $46.6 \%$ of the questions while in public clinics they asked about $34.7 \%$. That is, patients in both private and public practice settings ask 
questions and questions stand for power. Physicians' orders/ commands are in the form of bald on record, i.e., in conformity with Grice's maxims. They are given either in Phase III of conducting the examination or in phase V of detailing treatment. This indicates that they are given in the clearest, most direct and unambiguous form to achieve maximally efficient communication. They are not intended to express power superiority. This is illustrated by the frequent use of politeness strategies. A frequent utterance of positive politeness has been observed. They are used by physicians in the following linguistic realizations: (1) Use in group identity markers, (2) intensify to patients, (3) give reasons, (4) presuppose/raise/assert common ground, (5) include both physician and patient in the activity, (6) exaggerate approval and sympathy and (7) use joke. In this regard, the use of positive politeness by physicians in their interaction with patients indicates that patients are not powerless. Negative politeness has been also used frequently by physicians and patients to minimize the imposition of the FTAs. The following devices of negative politeness are identified: (1) State the FTA as a general rule, (2) minimize the imposition, (3) give deference, (4) the use of a hedge, (5) apologize and (6) impersonalize physician and patient.

Negative politeness and positive politeness are used to decrease and increase social distance in the relationship between physicians and patients which is a dynamic relationship. however, both negative and positive politeness are more common and frequent $\mathrm{m}$ private practice settings than in public clinics. The reason is due to the power asymmetry between physicians and patients. Moreover, the results show that participants in both private and public practice settings tend to use positive politeness more than negative politeness. This contrasts with Brown and Levinson's (1978) that in Western culture negative politeness is the most elaborate and most conventionalized set of linguistic strategies for FTA redress. Off record strategies are also used by physicians in the encounters. They invite conversational implicatures by violating the Gricean maxims. They are realized linguistically as: (1) Violate Manner Maxim: Be vague, overgeneralize, (2) Violate Relevance Maxim: Give hints and (3) Violate Quality Maxim: Use rhetorical questions. Yet, the number of off record utterances are few. This is due to the nature of medical interactions in which the achieving of maximally efficient communication is the most important aim.

Turn taking violations, i.e. overlap, interruption, and backchannel are also common in these encounters. They have two functions: first, they reflect the conversational nature of these encounters, and second, they illustrate the nature of the relationship between physicians and patients. The encounters include other conversational features such as adjacency pairs and the preference system. In private practice settings, two types of adjacency pairs have been observed, i.e., greeting/ greeting and question/answer pairs. By contrast, public clinics include only one type of adjacency pairs, namely, question/answer. However, participants in both private and public practice settings pay considerable attention to preferred versus dispreferred responses. Of the dispreferred responses observed are non-answers to questions versus answers. This results in participant repeating the question until s/she gets an answer. In this regard, Egyptian Arabic medical encounters are not interviews in which physicians ask questions and patients passively answer. They are purposeful conversations: both physicians and patients ask questions. They also include different conversational features: the use of politeness strategies, turn-taking violations, adjacency pairs and the related term preference. In these purposeful conversations, power is not stable. It is constantly renegotiated through discourse which provides participants with discursive power. That is, power is dynamic: it is possible for patients to gain discursive power temporarily though physicians have institutional and social power. To conclude, the asymmetrical relationship between physicians and patients in Egyptian Arabic medical encounters results from situated or institutional identities which physicians acquire by being representatives for an institutional setting. In public clinics, physicians exercise another type of power due to differences in social class. This is known as master identities. Besides, there is discourse identity that shifts between participants in the consultations. As pointed out above, there are no absolutely powerful and powerless participants in these encounters. Rather, both participants are active: they share power. In addition, the relationship between participants is a dynamic one in which there is an increase and decrease in the social distance through the use of different strategies of politeness. The encounters do not belong entirely to the interview genre which is characterized by questions and answers. They belong to "talk-in-interaction". They also have some characteristics of purposeful conversations such as turn-taking organization and co-operative principle.

\section{References}

Ainsworth-Vaughn, N. (1992). Topic transitions in physician-patient interviews: Power, gender, and discourse change. Language in society, 21, 409-26.

Ainsworth-Vaughn, N. (1994). Negotiating genre and power: Questions in medical discourse. In Text and Talk in Professional contexts (ed.) Britt-Louise Gunnarssion, Per Linell, and Bengt Nordstorm, 149-66.

Ainsworth-Vaughn, N. (1998). Claiming Power in Doctor-patient Talk. New York: Oxford University Press.

Al-Ali, M., 2006. Religious affiliations and masculine power in Jordanian wedding invitation genre. Discourse and Society, 17(6), 691-714.

Andersen, R. (1988). The Power and the Word: Language, Power, and Change. London: Collins.

Arnold, R.M., Martin, S. C. \& Parker, R.M. (1988). Taking care of patients does it matter whether the physician is a woman? Western Journal of Medicine, 149, 729-733.

Barry, D., Carroll, B. \& Hansen, H. (2006). To text or context? Endotextual, exotextual, and multi-textual approaches to narrative and discursive organizational studies. Organization Studies 27 (8), 1091-1110. 
Bialystok, E. (1993). Symbolic representation and attention control in pragmatic competence. In G. Kasper and S. BlumKulka (eds.), Interlanguage Pragmatics. New York/Oxford: OUP.

Biesker, A. E. \& Biesker T, D. (1990). Patient information seeking behaviors when communicating with doctors. Medical Care, 28, 1928.

Boisvert, D. \& Thiede, R. (2020). Language, Mind and Power. Routledge \& CRS Press.

Brown, P. \& Levinson, S.C. (1978). Politeness: Some Universals in Language Usage. Cambridge: Cambridge University Press.

Bucholtz, M. \& Hall, K. (2005). Identity and interaction: A sociocultural linguistic approach. Discourse Studies 7 (4-5): 585614.

Byrne, P.S. \& Long B.E.L. (1976). Doctors Talking to Patients: A Study of the Verbal Behaviours of Doctors in the Consultation. London: HMSO.

Campbell, S. \& Roberts, C., 2007. Migration, ethnicity and competing discourse in the job interview: Synthesizing the institutional and personal. Discourse and Society 18 (3), 243-271.

Daly, N., Holmes, J., Newton, J. \& Stubbe, M., 2004. Expletives as solidarity signals in FTAs on the factory floor. Journal of Pragmatics 36, 945-964.

De Fina, A., Schiffrin, D. \& Bamberg, M. (eds.). (2006). Discourse and Identity. Cambridge University Press.

Dillon, J.T. (1990). The Practice of Questioning. New York: Routledge.

Duffy F.D., Gordon G.H., Whelan G, et al. (2004). Assessing competence in communication and interpersonal skills. The Kalamazoo II report Acad Med. 79(6), 495-507.

El-dali, H. (2011). Meaning in Language Use: Reflections from pragmatics and discourse analysis - with special reference to political discourse. Annals of the Arts and Social Sciences, 32, 5-77.

El-dali, H. (2012). Narration and persuasion in English by Arabic and Spanish Speakers. Lambert Academic Publishing

El-dali, H. (2019a). Perfecting the theory of meaning: The story of pragmatics and discourse analysis. Advance in Social Science and Culture 1(1), 50-89.

El-dali, H. (2019b). The Language of consumer advertising: Linguistic and psychological perspectives. Studies in Linguistics and Literature, 3(2), 95-126.

Evans, B. (2018). Language, Society and Power, Routledge \& CRS Press.

Ezzat, A. G.E. (1972). Essays on Language and Literature. Berirut: Bouheiry Brothers.

Fairclough, N. (1989). Language and Power. London: Longman.

Fong Ha, J., Anat, D., \& Longnecker, N. (2010). Doctor-patient communication: A review. The Ochsner Journal 10, 10-38.

Frankel, R. (1990). Talking in interviews: A dispreference for patient-initiated questions in physician-patient encounters. In Psathas (ed.). Everyday Language: Studies in Ethnomethodology. New York: Irvington, 231-62.

Givon, T. (2005). Context as Other Minds: The Pragmatics of sociality, Cognition and Communication. Amsterdam: John Benjamins Publishing Company.

Gotti, M. \& Salager-Meyer, F. (2008). Advances in medical discourse analysis: Oral and written contexts. IBE Rica, 15, 177-202.

Hafez, O. (1988). Turn Taking in Egyptian Arabic: Spontaneous Speech Vs. Dramatic Discourse. Unpublished MA thesis: English Department, Faculty of Arts, Cairo University.

Hall, J.A, Rater DL, Rand CS. (1981). Communication of affect between patient and physician. J Health Soc Behav, 22(1), 18-30.

Hammudin, B. (2012). A Comparative Study of Politeness Strategies in Economic Journals. Doctoral Dissertation, University of Malaya.

Hardavella, G., Aamli-Gagnat, A. and Frille, A. (2017). Top tips to deal with challenging situations: Doctor-patient interactions. Breathe, 13, 129-135.

Harris, S. (2003). Politeness and power: Making and responding to requests in institutional settings. Text, $23,27-52$.

Hart, C. (2020). Researching Discourse: A Student Guide, Routledge \& CRS Press.

Have, Paul Ten (1999). Doing Conversation Analysis: A practical guide. London: Sage Publications.

Haworth, K. (2006). The dynamics of power and resistance in police interview discourse. Discourse and Society, 17 (6), 739-759.

Heath, C. (1992). The delivery and reception of diagnosis in the general practice consultation. In P. drew and J. Heritage (eds.), Talk at Work. Cambridge: Cambridge University Press. Pp. 235-67.

Heydon, G. (20050. The Language of Police Interviewing: A Critical Analysis. Basingstoke, UK: Palgrave.

Hirsch, S.F. (1994). Research on language and power: Talking empowerment? Journal of Linguistic Anthropology, 4(2), 215-22.

Holmes, J. (2005). Power and discourse at work: Is gender relevant? In M. Lazar (ed.), Feminist Critical Discourse Analysis: Gender, Power and Ideology in Discourse. Basingstoke, UK: Palgrave.

Jiang, X. (2006). Cross-cultural pragmatic differences in US and Chinese press conferences: The case of the North Korea nuclear crisis. Discourse and Society, 17(2), 237-257.

Kamp, H. and Partee, B. (eds.) (2004). Context-dependence in the Analysis of Linguistic Meaning. Amsterdam, Boston: Elsevier. 
Kendon, A. (1982). the organization of behaviour in face-to face interaction: Observations in the development of a methodology. In K.R. Scherer and P. Ekman (eds.) Handbook of Methods in Nonverbal Behaviour Research, pp. 440505. Cambridge: Cambridge University Press.

Levinson, S. (1992). Activity types and language. In P. Drew and J. Heritage (eds.), Talk at Work, 66-100.

Linn, L.S., Cope, and Leak, B. (1984). The effect of gender and training of residents on satisfaction rating by patients. Journal of Medical Education, 59, 964-66.

Maltz, D.N., and R.A. Borker (1982). A cultural approach to male-female miscommunication. In J.J. Gumperz (ed), Language and Social Identity. Cambridge: Cambridge University Press.

McKellin, W., Shahin, K. and Hodgson, M. (2007). Pragmatics of conversation and communication in noisy settings. Journal of Pragmatics, 39, 2159-2184.

Mooney, A., Peccel, J. and La Belle, S. (2011). The Language, Society and Power, Routledge \& CRS Press.

Peck, B. (2011). Age-related differences in doctor-patient interaction and patient satisfaction. Hindawi Publishing Corporation, 42-52.

Pizzini, F. (1991). Communication hierarchies in humor: Gender differences in the obsterical gynecological setting. Discourse and Society, 2(4), 477-88.

Roter, D.L. (1977). Patient participation in the patient-provider interaction: The effects of patient question asking on the quality of interaction, satisfaction, and compliance. Health Education Monographs, 5, 281-315.

Sacks, H. (1987). On the preference for agreement and contiguity in sequences in conversation. In G. Button and J.R.E. Lee (eds.), Talk and Social Organization. Clevedon: Multilingual Matters, 54-69.

Sacks, H. (1992). Lectures on Conversation. edited by G. Jefferson. Oxford: Blackwell.

Schegloff, E.A. (1972). Notes on a conversational practice: formulating place. In D. Sudnow (ed.), Studies in Social Interaction. New York: Free Press. 75-119.

Schegloff, E.A. (1987). Some sources of misunderstanding in talk-in-interaction. Linguistics, 25, 201-18.

Silverman, D., 1987. Communication and Medical Practice. London: Sage.

Simpson, P., Mayar, A. and Statham, S. (2018). Language and Power: A Resource Book for Students, Routledge \& CRS Press.

Tongue J.R., Epps HR, Forese L.L. (2005). Communication skills for patient centered care: research-based, easily learned techniques for medical interviews that benefit orthopedic surgeons and their patients. J Bone Joint Surg Am., 87, 652658.

Van Dijk, T. (2006). Discourse, context and cognition. Discourse Studies, 8 (1), 159-177.

Van Dijk, T. (2008a). Discourse and Context: A Sociocognitive Approach. Cambridge University Press.

Van Dijk, T. (2008b). Society and Discourse: How Context Controls Text and Talk. Cambridge University Press.

Wang, J. (2006). Questions and the exercises of power. Discourse and Society, 17 (4), 529-548.

Widdowson, H. (2004). Text, Context, Pretext: Critical Issues in Discourse Analysis. Oxford: Blackwell.

Wilce, J. (2009). Medical course. Department of Anthropology, Northern Arizona University, Flagstaff, pp. 199-215.

Yazdannink, A. and Mohammadi, S. (2017). Discourse analysis: A useful methodology for health care system researches. Journal of Education and Health, Princeton, 6, 1-7.

Zimmerman, D.H., \& West, C. (1985). Sex roles, interruptions and silences in conversation. In B. Thome and N. Henley (eds.), Language and sex: Difference and dominance. Rowley, MA: Newbury House, 105-29. 